\title{
Educação ambiental na reconstituição da mata Ciliar do Ribeirão da Penha e aumento da arborização urbana no município de Itapira - SP
}

\author{
Environmental education in the reconstruction of bordering river Ribeirão da Penha and increase \\ in the urban trees the city of Itapira - SP \\ Anderson Martelli', Mariana de Moraes Cardoso² \\ ' Faculdade Mogiana do Estado de São Paulo, Mogi Guaçu- SP, Brasil \\ ${ }^{2}$ Engenheira Ambiental da Secretaria de Agricultura e Meio Ambiente de Itapira - SP, Brasil
}

\section{Resumo}

Atualmente, a preocupação com o ambiente está presente na vida de grande parte da população. Neste artigo discute-se a importância da mata ciliar, áreas degradadas pela ação antrópica e a recuperação da vegetação ciliar encontrada na área urbana através de ações de educação ambiental desenvolvidas pela Secretaria de Agricultura e Meio Ambiente de Itapira. Essa faixa de vegetação exercem a função de barreira e proteção das nascentes e cursos d'água, servindo como corredores ecológicos, unindo fragmentos de matas permitindo o trânsito de animais e retirando-os do isolamento. As matas ciliares são protegidas por lei, mas, ainda existem áreas que vêm sendo desmatadas e outras que continuam degradadas sem a recomposição vegetal. Apesar da importância, o tema é pouco debatido e estudado, especialmente no meio acadêmico. O presente artigo retrata a reconstituição de uma área ciliar na margem do Ribeirão da Penha, principal curso d'agua que corta todo o perímetro urbano do Município de Itapira-SP e de onde provém a água que o abastece, com o plantio de 150 mudas de arvores por alunos do $8^{\circ}$ ano da Escola Ativa enfatizando o trabalho de educação ambiental.

Palavras-chave: Matas Ciliares, Arborização Urbana, Educação Ambiental, Recuperação, Itapira.

\begin{abstract}
Nowadays, a concern for the environment is present in the lives of most of the population. This article discusses the importance of bordering river, degraded areas by human action and recovery of ciliary vegetation found in urban areas through environmental education program developed by the Department of Agriculture and Environment Itapira. This strip of vegetation carry out action the barrier function and protection of water sources and water courses, server as ecological passageway, linking forest fragments allowing the transit of animals, taking them out of isolation. Bordering river are secured by law, but, there are still areas that have been deforested and degraded others who continue without recomposition plant. Although the importance the topic is rarely discussed and studied, especially in academic. This article portrays the reconstruction of bordering river on the riverside of Ribeirão da Penha, the main water course that cuts through the city limits of the Itapira-SP City and where water comes from the provide tanks, with the planting of 150 trees by students in the 8th year Ativa school emphasizing environmental education.
\end{abstract}

Keywords: bordering river, urban tree planting, environmental education, reconstruction, Itapira. 


\section{INTRODUÇÃO}

O desenvolvimento do Brasil ocasionou, dentre outros impactos ambientais, o desaparecimento de grande parte da cobertura vegetal original do país, auferindo riquezas econômicas e utilizando dos seus recursos naturais disponíveis. Esse emprego não se deu de maneira sustentável, gerando assim passivos ambientais a serem recuperados (ANDRADE et al., 2005).

Ao longo dos anos, as áreas de preservação permanente (APP's) às margens dos cursos d'água vêm sofrendo degradações, principalmente nas áreas urbanas, com a retirada parcial ou total da vegetação nessa faixa, a qual deveria ser mantida intacta por garantir a preservação dos recursos hídricos, a estabilidade geológica e a biodiversidade (TERRES; MULLER, 2008; ANDRADE et al., 2005; DURIGAN; SILVEIRA, 1999).

As matas ciliares são formações vegetais que se encontram associadas aos corpos d'água, ao longo dos quais podem se estender por dezenas de metros a partir das margens e apresentar marcantes variações na composição florística e na estrutura comunitária, dependendo das interações que se estabelecem entre o ecossistema aquático e o ambiente terrestre adjacente (MARTINS, 2001; ANDRADE et al., 2005, CHAVES, 1999; ALVARENGA, 2004).

A função das matas ciliares em relação às águas está ligada a sua influência sobre uma série de fatores importantes. Entretanto, nem sempre são respeitados os limites mínimos para as APP's, pois o processo de urbanização resulta em pressão antrópica diversa nesse ambiente. Este processo de degradação das formações ciliares, além de desrespeitar a legislação vigente, que torna obrigatória a preservação das mesmas, resulta em vários problemas ambientais (TERRES; MULLER, 2008).

Segundo o novo Código Florestal Brasileiro, Lei n ${ }^{\circ} 12.651$ de 25 de Maio de 2012, em seu artigo $3^{\circ}$, seção II, entende-se por área de preservação permanente: área protegida, coberta ou não por vegetação nativa, com a função ambiental de preservar os recursos hídricos, a paisagem, a estabilidade geológica, a biodiversidade, o fluxo gênico de fauna e flora, proteger o solo e assegurar o bem estar das populações humanas.

Devido a sua importância, as APP's deveriam estar de fato protegidas pela legislação ambiental, mas o que se verifica é que as normas que regulam essas áreas têm sido ignoradas, principalmente na área urbana, devido às práticas industriais, imobiliárias, falta de planejamento urbano, muitas vezes com a conivência do poder público, tendo, quase sempre, como motivação a oferta de empregos e o progresso econômico (ANDRADE et al., 2005).

Apesar de sua inegável importância ambiental, as matas ciliares vêm sendo degradadas em várias partes do Brasil. Entre os inúmeros fatores que têm contribuído para isso, destacam-se os desmatamentos, incêndios e represamentos (ANDRADE et al., 2005).

Aliado a esses fatores, é possível observar áreas ocupadas anteriormente ao surgimento de algumas leis que tratam desses fins, levando os moradores dessas áreas a terem direitos constituídos, dificultando assim, os processos de desocupação das áreas que deveriam ser preservadas (TERRES; MULLER, 2008).

Segundo Araújo (2002), ao longo dos cursos d'água, deveriam ser observadas todas as normas que regulam as APP's. Na prática, essas e outras APP's têm sido simplesmente ignoradas na maioria dos núcleos urbanos, associando-se a graves prejuízos ambientais como a formação de voçorocas, perda de solo, assoreamento e contaminação dos corpos d'água.

Para Martins (2001) e Andrade et al., (2005), as matas ciliares funcionam como filtros, retendo defensivos agrícolas, poluentes e sedimentos que seriam transportados para os cursos d'água, afetando diretamente a quantidade e a qualidade da água e, conseqüentemente, a fauna aquática e a população humana. São importantes, também, como corredores ecológicos, ligando fragmentos florestais e, portanto, facilitando o deslocamento da fauna e o fluxo gênico entre as populações de espécies animais e vegetais.

Em regiões com topografia acidentada, essa vegetação exerce a proteção do solo contra os processos erosivos intensos, pois suas raízes servem como fixadoras do solo das margens (RIZZO, 2007).

Segundo Coelho Neto (1995), a cobertura vegetal tem como uma de suas múltiplas funções o papel de interceptar parte da precipitação. Assim, os solos sem cobertura florestal reduzem drasticamente sua capacidade de retenção de água de chuva, ou seja, em vez de infiltrar no solo, ela escoa sobre a superfície formando enormes enxurradas que não permitem o bom abastecimento do lençol 
freático, promovendo a diminuição da água armazenada e, com isso, a redução do número de nascentes. As conseqüências do rebaixamento do lençol freático, contudo, não se limitam às nascentes, mas se estendem aos córregos, rios e riachos abastecidos por ele.

Além disso, a ausência das sombras geradas pelas matas ciliares altera a temperatura da água, principalmente no verão. As margens sombreadas são locais habitados por microorganismos, peixes e outros organismos aquáticos. A redução ou o desaparecimento dessas espécies causa um desequilíbrio ecológico e a perda da diversidade da fauna aquática (PALONE, 1997; NAIMAN; DÉCAMPS, 1997)

O que se pode observar atualmente, é que mesmo com os prejuízos causados pela ausência da faixa de preservação permanente, ainda não há uma conscientização da população em relação a esse tema, mesmo entre aqueles que têm conhecimento da legislação ambiental (TERRES; MULLER, 2008).

Este estudo retrata o reflorestamento de uma APP dentro do perímetro urbano do município de Itapira, neste sentido, Martelli e Barbosa Jr. (2010) relatam em seu estudo a importância da árvore no meio urbano por todas suas funções desempenadas, ganhando uma maior relevância quando a concentração das habitações aumenta.

Atualmente a gestão do programa de reconstituição de mata ciliar e arborização urbana no município de Itapira - SP é de responsabilidade da Secretaria de Agricultura e Meio Ambiente de Itapira - SP (SAMA), órgão vinculado à Prefeitura Municipal, assim, um caminho encontrado para o aumento da arborização urbana foi o plantio de árvores nas APP's que margeiam os córregos e ribeirões encontrados na área urbana do município.

Paralelo a essas ações de reconstituição de mata ciliar e arborização urbana, a SAMA atua com sua equipe técnica para a realização de plantios e explanações sobre o tema e sua importância para a melhor qualidade de vida dos munícipes, trabalhando a educação ambiental (EA) nas escolas píblicas e privadas e demais instituições sociais, aumentando a sensibilidade nos alunos e consequentemente um aumento visível de árvores no meio urbano, sendo um caminho na preservação e melhoramento dos aspectos ambientais.

Segundo Dias (2004), as ações de EA é um processo permanente na qual os indivíduos e a comunidade tomam consciência do seu meio ambiente e adquirem conhecimentos, valores, habilidades, experiências e determinação que os tornem aptos a agir e resolver problemas ambientais, presentes e futuros.

Segundo Andrade e Santo (2010), o trabalho da educação ambiental, dentro do contexto da prática pedagógica, deve ser desenvolvido a fim de ajudar os alunos a construírem uma consciência global das questões relativas ao meio, para que possam assumir posições afinadas com os valores referentes à sua proteção e melhoria.

As atividades de campo constituem importante estratégia para o ensino, uma vez que permitem explorar uma grande diversidade de conteúdos, motivam os estudantes, possibilitam o contato direto com o ambiente e a melhor compreensão dos fenômenos (VIVEIRO; DINIZ, 2009).

Para isso, é importante que possam atribuir significado àquilo que aprendem sobre as questões ambientais. Esse significado é resultado da ligação que o aluno estabelece entre o que aprende e a sua realidade cotidiana, da possibilidade de estabelecer ligações entre o que aprende e o que conhece, e também da possibilidade de utilizar esse conhecimento em outras situações (ANDRADE; SANTO, 2010).

Levando em consideração a importância da mata ciliar para o bem estar da população e por ser um tema pouco divulgado, esse trabalho apresenta como objetivo mostrar a importância da interação entre reconstituição de uma área de mata ciliar favorecendo a arborização urbana local por se tratar de uma área urbana do municipio de Itapira -SP e a EA, através de plantios de árvores nativas na margem de um corpo d'agua denominado Ribeirão da Penha a qual sofre com ações antropogênicas, junto aos estudantes do $8^{\circ}$ ano ensino fundamental da Escola Ativa e uma maior divulgação sobre a importância desta ação para o município.

\section{MATERIAIS E MÉTODOS}

\section{I CARACTERIZAÇÃo do MUNICÍPIO de ITAPIRA}

O Município de Itapira integra a Região Administrativa de Campinas e está localizado na região Sudeste, porção centro-leste do Estado de São Paulo, a 22 $26^{\prime} 10^{\prime \prime}$ de latitude S e $46^{\circ} 49^{\prime} 18^{\prime \prime}$ de 
longitude W, distando aproximadamente $63 \mathrm{~km}$ (via anel de contorno) da cidade de Campinas e 159 km da capital do Estado.

Possui uma área de $518,385 \mathrm{~km}^{2}$, com uma estimativa populacional de 68.537 habitantes. $\mathrm{O}$ perímetro urbano apresenta uma área de $58.042 \mathrm{~m}^{2}$ com uma densidade demográfica de 132,21 habitantes por $\mathrm{km}^{2}$ (IBGE, 2010).

Acha-se incluído na "Serrania de Lindóia", segundo subdivisão geomorfológica do Estado de São Paulo proposta no Mapa Geomorfológico do Estado de São Paulo (IPT, 2006). Limita-se a oeste, com a "Zona do Mogi Guaçu", uma das três subdivisões propostas para as Depressões Periféricas Paulista, representadas pelas rochas da Bacia do Paraná.

O clima predominante na região é o Temperado Quente Úmido, de acordo com classificação de Köppen, havendo estações com mais de 60 dias secos, com temperatura máxima anual em cerca de $29^{\circ} \mathrm{C}$ e temperatura mínima anual em cerca de $5^{\circ} \mathrm{C}$, com médias anuais de precipitação em torno de $1.600 \mathrm{~mm}$ (SETZER,1976).

A área de escolha do plantio situa-se no perímetro urbano do município de Itapira no bairro denominado Conjunto Habitacional Della Rocha III, numa área de APP, paralelo ao Ribeirão da Penha principal curso d'agua do município o qual corta todo o perímetro urbano conforme demonstrado na figura 1.

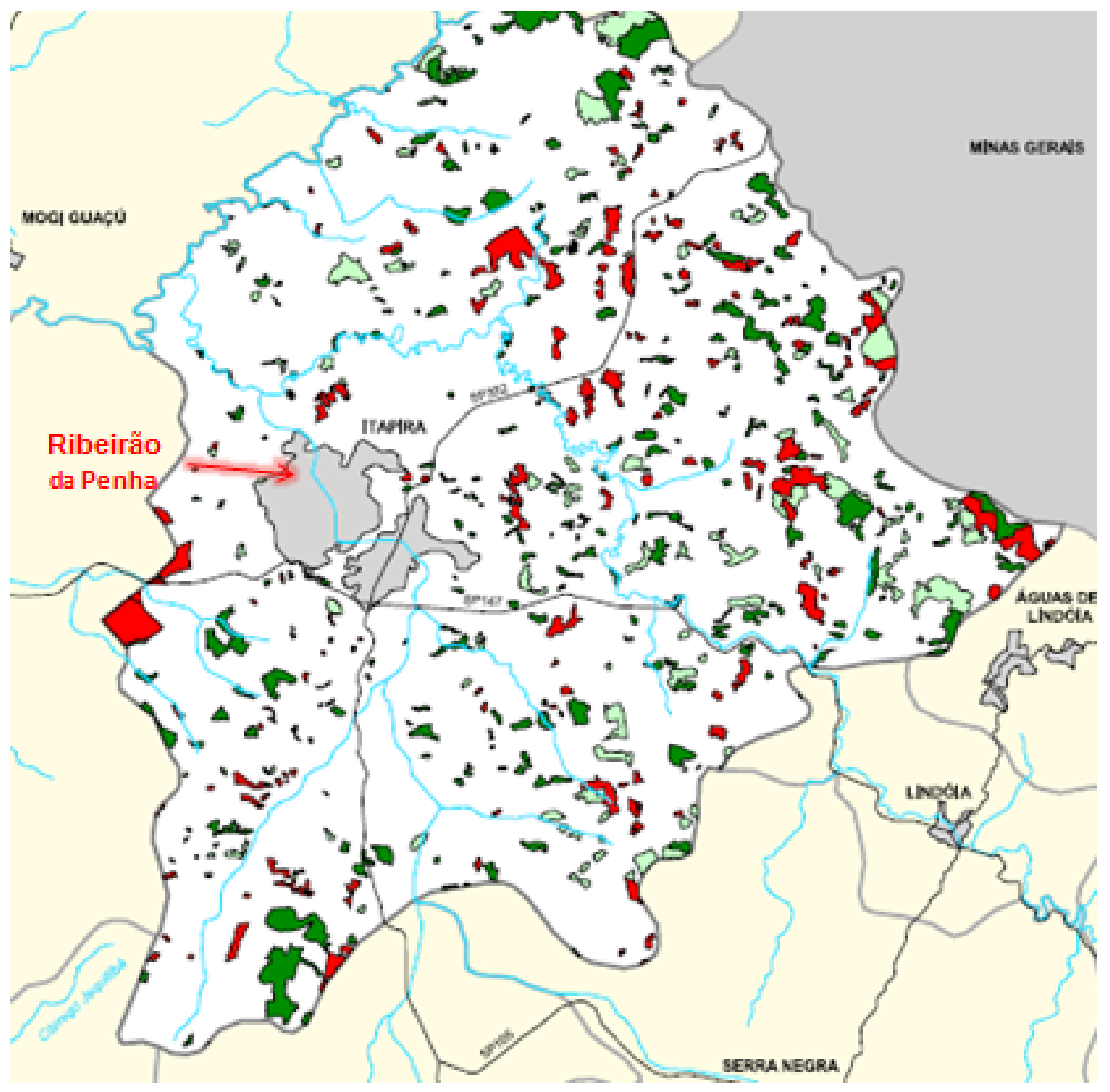

Figura 1. Área total do município de Itapira-SP mostrando o Ribeirão da Penha cortando o perímetro urbano (área cinza) 
Segundo estudo de Silveira e Bueno (2008), a área delimitada pela microbacia do Ribeirão da Penha em Itapira, é marcada por diversas ações antrópicas, como a retificação do Ribeirão da Penha, a construção de barragens, além da presença constante de ocupação em grande parte das vezes não planejada ou planejada, mas sem vistas aos aspectos ambientais e sociais.

Para a reconstituição ciliar junto aos alunos da Escola Ativa, técnicos especializados da SAMA dirigiram-se ao respectivo local de plantio no dia 17 de Dezembro de 2011, onde realizaram a marcação dos locais a serem realizados os coveamentos para posterior plantio.

\subsection{TÉCNICA DE PREPARO DA ÁREA DO PLANTIO}

O preparo do terreno para plantio compreendeu com uma roçada mecanizada da vegetação existente (predominantemente gramíneas). Posteriormente funcionários do viveiro municipal de mudas foram até o local demarcado e realizaram o coroamento manual utilizando enxadas, com cerca de 60 $\mathrm{cm}$ de diâmetro para cada cova. Em seguida um trator do tipo Valmet 108 acoplado com um perfurador de solo realizou a abertura das covas com dimensões de aproximadamente 30 centímetros de diâmetro por 40 centímetros de profundidade. O solo referente aos coveamentos foi misturado com $20 \%$ do volume da cova com adubo orgânico (esterco de curral) e o retorno deste solo a seu respectivo buraco.

Uma semana antes do plantio foi realizada a separação das mudas no Viveiro Municipal vinculado a SAMA. No dia 23, as mudas foram transportadas até o local de plantio, sendo distribuídas próximas às covas que foram abertas, combinando espécies dos diferentes estádios de sucessão (pioneiras, secundárias e clímax), adaptadas às condições locais. Posteriormente, funcionários da SAMA retiraram o solo dos coveamentos de acordo com o volume dos torrões das mudas dispostas.

Com a chegada dos alunos, foi realizado as orientações pertinentes para a realização do plantio, assim como, enfatizado a importância da ação de reconstituição da mata ciliar dos cursos d'agua e como esta ação estava favorecendo a arborização urbana do município sendo, posteriormente, iniciada a ação.

\section{RESULTADOS E DISCUSSÃO}

Para o plantio realizado na APP localizada na margem do Ribeirão da Penha, município de Itapira-SP, foram selecionadas um total de 150 unidades, sendo 136 mudas de espécies nativas representando $90,70 \%$ das mudas plantadas e o restante, 14 mudas $(9,30 \%)$ exóticas adaptadas a nossa região.

A distribuição das mudas foram estabelecidas levando em consideração seu estado sucessional, onde as espécies pioneiras e secundárias iniciais, de rápido crescimento, venham a sombrear e favorecer um ambiente às mudas das espécies que se desenvolvem melhor à sombra - secundárias tardias e climáceas.

Alunos e professores formaram duplas e percorreram os coveamentos realizando o plantio das espécies selecionadas (Figura 2), possibilitando a cada jovem colocar em prática o que aprenderam. Técnicos da SAMA revisaram as mudas plantadas e colocaram os tutores para direcionamento de crescimento e proteção de fatores climáticos extremos - ventos.

Após as orientações aos alunos pertinentes ao plantio, os benefícios da reconstituição da mata ciliar para o meio ambiente e para o curso d'agua em questão e levando em consideração do local se tratar de uma área urbana favorecendo desta forma a arborização urbana, foi observado uma percepção de grande motivação e curiosidades dos alunos quanto ao período de desenvolvimento das plantas, de que forma são produzidas, identificação das espécies, características morfológicas, aspectos paisagísticos "fenologia" dentre outros, favorecendo a aprendizagem adquirida em sala de aula, corroborando com as análises realizadas por Santos (2002), onde as contribuições da aula de campo de Ciências e Biologia em um ambiente natural podem ser positivas na aprendizagem dos conceitos à medida que são um estímulo para os professores, que vêem uma possibilidade de inovação para seus trabalhos e assim se empenham mais na orientação dos alunos.

Segundo Seniciato e Cavassan (2004), as aulas desenvolvidas em ambientes naturais têm sido apontadas como uma metodologia eficaz tanto por envolverem e motivarem crianças e jovens nas atividades educativas, quanto por constituírem um instrumento de superação da fragmentação do conhecimento.

A ação antrópica faz o espaço, o território, o lugar, a região e a paisagem se alterarem. Ao iniciar as atividades neste local foi percebido a ação antrópica com o deposito de resíduos sólidos nas 



Figura 2. Reconstituição da mata ciliar por alunos e professores na margem do Ribeirão da Penha. Em A, as orientações para o plantio, em B, C e D formação de duplas e o plantio das mudas

margens desse ribeirão. Após a retirada deste resíduos e posterior plantio observou-se um melhora significativa neste aspecto. Assim a ação local envolvendo instituições e membros da sociedade constrói uma nova dinâmica no município em defesa das matas ciliares, aumento da arborização urbana e, conseqüentemente, dos cursos d'água.

Apesar de ser indiscutível que os problemas ambientais devam estar entre os assuntos prioritários na sociedade moderna e que as aulas de campo são um instrumento eficiente para o estabelecimento de uma nova perspectiva na relação entre o homem e a natureza, o plantio de arvores no campo com os alunos, favoreceu também, o trabalho coletivo em equipe visando uma ação harmoniosa e cooperativa em busca de um mesmo objetivo e a aquisição da responsabilidade do cuidar junto à atividade desenvolvida. As atividades de campo permitem também a exploração de conteúdos conceituais, procedimentais e atitudinais, o que possibilita que sejam também de grande valia em programas de EA.

Portanto, a prática da EA, como transmissora de procedimentos ambientalmente corretos, nem sempre garantirá a formação de atitudes ecológicas, sendo que o indivíduo apenas agirá de acordo com o que se espera dele. A formação de uma atitude ecológica está intimamente relacionada com o sistema de valores que orientam as relações do indivíduo com o meio, o que, conseqüentemente, norteará os posicionamentos na escola, assim como, em outros espaços de sua vida (CARVALHO, 2006).

As atividades de campo permitem também o contato direto com o ambiente, possibilitando que o estudante se envolva e interaja em situações reais. Assim, além de estimular a curiosidade e aguçar os sentidos, possibilita confrontar teoria e prática.

\section{CONSIDERAÇÕES FINAIS}

Por muito tempo, a sociedade aceitou a degradação das matas ciliares e, hoje, estamos colhendo os frutos dessas ações. A partir das ações de mobilização da sociedade e do atendimento da Prefeitura Municipal de Itapira através da SAMA, observa-se a formação de uma rede entre o órgão público, 
comunidades, escolas e outros órgãos, onde permeiam não somente atitudes pontuais relacionadas às questões ambientais, mas também ações e iniciativas futuras desses órgãos no que se refere à educação ambiental para o município. Outro aspecto importante é verificar a necessidade de maior sensibilização dos alunos na questão sobre mata ciliar, arborização urbana e meio ambiente, onde após realizar o plantio percebeu-se um comprometimento dos jovens no sentido de voltar ao local de plantio com familiar e acompanhar as mudas plantadas.

Portanto, a informação aliada a uma atitude construtiva, geram ações que podem mudar a visão dos jovens em relação ao meio ambiente que os cercam, e gerar cidadãos com um olhar ampliado para mundo. Essa cumplicidade entre todas as esferas presentes no espaço urbano é a condição básica para o alcance de uma melhor qualidade ambiental urbana e um padrão mínimo de qualidade de vida humana. Neste sentido, a educação ambiental é uma ferramenta na realização de ações para melhoria da região, intensificando-se, com isto, a demanda por atividades que estimulem o desenvolvimento de uma consciência ambiental, não só ecológica, do ponto de vista da natureza, mas também visando às questões social, cultural e econômica.

\section{REFERÊNCIAS}

ALVARENGA, A. P. Avaliação inicial da recuperação da mata ciliar em nascentes. 175 f. Dissertação (Mestrado em Engenharia Florestal). Universidade Federal de Lavras, UFLA, 2004.

ANDRADE, J.; SANQUETTA, C. R.; UGAYA, C. Identificação de Áreas Prioritárias para Recuperação da Mata Ciliar na UHE Salto Caxias. Espaço Energia, n. 3, 2005.

ANDRADE, K. C. M.; SANTO, M. E. P. A Arborização Como Prática da Educação Ambiental na Escola Lions de Parnamirim. In: JORNADA DE ENSINO, 10, 2010, Recife. PESQUISA E EXTENSÃO. Pernambuco: Jepex, 2010. Disponível em: <http://www.sigeventos.com.br/jepex/inscricao/resumos/0001/R0153-1. PDF>. Acesso em: 27 nov. 2011.

ARAÚJO, S. M. V. As Áreas de Preservação Permanente e a Questão Urbana. Brasília-DF, p. 03, 2002.

BRASIL, Novo Código Florestal, Lei no 12.651, de 25 de maio de 2012. Disponível em: < http://saema.com. br/files/Novo\%20Codigo\%20Florestal.pdf > Acesso em: 02 de Janeiro de 2012.

CARVALHO, I. C. M. Educação ambiental: a formação do sujeito ecológico. 2 ed. São Paulo: Cortez, p.255, 2006.

CHAVES, M. M. F. Reflorestamentos Mistos com Essências Nativas para Recomposição de Matas Ciliares. Boletim Agropecuário. Lavras: UFLA, 1999.

COELHO NETO, A. L. Hidrologia de encosta na interface com a Geomorfologia. In: GUERRA, A. J. T. Geomorfologia: uma atualização de bases e conceitos. 2. ed. Rio de Janeiro: Bertrand Brasil, 1995. p. 93-145.

DIAS, G. F. Educação Ambiental - Princípios e Práticas . 9. ed. Gaia Brasil, 2004.

DURIGAN, G.; SILVEIRA, E. R. Recomposição de mata ciliar em domínio de cerrado, Assis, SP. Scientia Florestalis, v. 56, p.135-144, 1999.

INSTITUTO BRASILEIRO DE GEOGRAFIA E ESTATÍSTICA - IBGE Cidades: Censo 2010 Disponível em: <http://www.ibge.gov.br/cidadesat/topwindow.htm?1 > Acesso em 22 de dezembro, 2011.

INSTITUTO FLORESTAL - SIFESP: Sistema de Informações Florestais do Estado de São Paulo. Disponível $\mathrm{em}:<$ http://www.iflorestal.sp.gov.br/sifesp/estadosaopaulo/itapira.pdf?opcoes=itapira.pdf $>$ acesso em 18 Dezembro/2013. 
INSTITUTO DE PESQUISAS TECNOLÓGICAS DO ESTADO DE SÃO PAULO S.A. - IPT. Mapeamento geológico na escala 1:50.000 das folhas Mogi Guaçu e Águas de Lindóia, 1982. Disponível em: < http:// www.ipt.br > Acesso em: 05 jan. 2007.

MARTELLI, A.; BARBOSA JUNIOR, J. Análise da Incidência de Supressão Arbórea e Suas Principais Causas No Perímetro Urbano do Município de Itapira-SP. Revista da Sociedade Brasileira de Arborização Urbana, Piracicaba, v. 5, n. 4, p.96-109, 2010.

MARTINS, S. V. Recuperação de matas ciliares. Ed. Aprenda fácil. Viçosa - MG, 2001.

NAIMAN, R.J.; DECAMPS, H. 1997. Ecology of Interfaces: Riparian Zones. Annual Reviews in Ecological Systems, v. 28, p. 621-658, 1997.

PALONE, R. S.; TODD, A. H. Chesapeake Bay Riparian Handbook: A guide for establishing and maintaining riparian forest buffers. USDA Forest Service, NA-TP-02-97. Radnor-PA, 1997.

RIZZO, M. R. A RECOMPOSIÇÃO DAS MATAS CILIARES - UM BOM EXEMPLO QUE VEM DE PEDRO GOMES (MS) Revista Eletrônica da Associação dos Geógrafos Brasileiros - Seção Três Lagoas Três Lagoas - MS, v. 1, n. 6, 2007. Disponível em: < http://www.ceul.ufms.br/revista-geo/Artigo5 M.Rizzo.pdf> Acesso em: 02 de jan. 2012.

SANTOS, S. A. M. A excursão como recurso didático no ensino de biologia e educação ambiental. In: VIII ENCONTRO PERSPECTIVAS DO ENSINO DE BIOLOGIA, 6, São Paulo: FEUSP, 2002.

SENICIATO, T.; CAVASSAN, T. O. Aulas de Campo em Ambientes Naturais e Aprendizagem em Ciências Um Estudo com Alunos do Ensino Fundamental. Ciência \& Educação, v. 10, n. 1, p. 133-147, 2004.

SETZER, J. Atlas Climático do Estado de São Paulo. Secretaria da Agricultura. São Paulo, 1976.

SILVEIRA, A. F.; BUENO, L. M. M. Estudos de vulnerabilidade sócioambiental e usos do território na microbacia do Ribeirão da Penha - Itapira-SP Anais do XIII Encontro de Iniciação Científica da PUC-Campinas, 2008. Disponivel em: <http://www.puc-campinas.edu.br/pesquisa/ic/pic2008/resumos/ Resumo/\%7B1D573D1D-BC9B-4381-8690-F1079DF4C01E\%7D.pdf> Acesso em: 02 de Janeiro 2012.

TERRES, C. A.; MÜLLER, M. M. L. Proposta de recuperação de área degradada às margens do Arroio do Engenho na Vila Concórdia, Guarapuava - PR. UNICENTRO - Revista Eletrônica Lato Sensu, n. 5, 2008. Disponível em: < http://web03.unicentro.br/especializacao/Revista Pos/P\%C3\%A1ginas/5\%20 Edi\%C3\%A7\%C3\%A3o/Agrarias/PDF/2-Ed5 CAPropo.pdf> Acesso em: 03 de jan. 2012.

VIVEIRO, A. A.; DINIZ, R. E. S. Atividades de campo no ensino das ciências e na educação ambiental: refletindo sobre as potencialidades desta estratégia na prática escolar. Ciência em Tela, v. 2, n.1, 2009. 